\title{
Microtexture and nanoindentation study of delamination cracking in Al-Cu-Li-X alloys
}

\author{
R. Crooks ${ }^{1}$, M. S. Domack ${ }^{2} \&$ J. A. Wagner ${ }^{2}$ \\ ${ }^{1}$ National Institute of Aerospace, Hampton, Virginia, USA \\ ${ }^{2}$ NASA Langley Research Center, Hampton, Virginia, USA
}

\begin{abstract}
Commercial Al-Li alloys have strength and weight advantages over non-Al-Li alloys. The fracture behavior of these alloys is unusual and has limited their use. The fracture mode, described as delamination, is intergranular, along the broad grain boundaries parallel to the rolling plane of the plate. Microtexture analyses have shown that delaminations occur along boundaries with greater than $30^{\circ}$ misorientation. However, it was observed that relatively few of the high angle boundaries exhibited this behavior. Some grains of the retained deformation texture show high internal misorientation, which is a measure of stored strain energy. Delamination tends to occur between these grains and adjacent, recrystallized grains. Nanoindentation studies indicate a higher hardness for the high internal misorientation grains. These results suggest that the delamination could be reduced by processing the alloys to minimize grain-to-grain property disparities.
\end{abstract}

Keywords: microtexture, nanoindentation, Al-Li, delamination.

\section{Introduction}

Fracture in aluminum aerospace alloys typically occurs by ductile rupture and/or transgranular shear. Al-Li alloys saw renewed interest in the 1980's as a low density, high strength alternative to conventional aerospace Al alloys [1]. In addition to exhibiting ductile rupture and transgranular shear, many Al-Li plate alloys in the T8 temper (stretched and age hardened), exhibit delamination fracture. The intergranular fracture in these alloys is referred to as delamination because fracture along the characteristically thin, elongated grains resembles the separation of a laminated material. When the primary crack is perpendicular to 
the rolling plane in the LT or TL orientation, the triaxial stress state near the crack tip can be sufficient to separate grain boundaries susceptible to delamination.

The propensity of Al-Li alloys to delaminate has limited their use in aerospace applications and is due in part, to the absence of aerospace design tools to account for delaminations. Development of mechanistic models that describe delamination fracture behavior could help guide the modification of ingot processing to reduce the tendency for this type of fracture, thereby allowing designers and fabricators to realize the full benefits of Al-Li alloys.

There are several theories to explain this tendency for intergranular fracture. Based on recent journal publications, there are at least three current and competing explanations for this behavior. These can be described as planar slip, grain boundary precipitation, and grain boundary segregation.

The planar slip explanation has been strongly advocated by Sanders and Starke [2] and Csontos and Starke [3]. The reasoning is that intense planar slip bands arise due to the presence of shearable precipitates, e.g. the $\delta, \mathrm{Al}_{3} \mathrm{Li}$ phase. Shearing of the precipitates reduces the resistance to dislocation glide within the slip system and promotes planar slip. Planar slip bands cause intense stress concentrations at grain boundaries and promote intergranular fracture. Planar slip and precipitate shearing also occur in Al-Li-X alloys where the $\delta^{\prime}, \mathrm{Al}_{3} \mathrm{Li}$ precipitates are not the dominant strengthening phase. This is evident in the shearing of the higher strength ternary $\mathrm{T}_{1}, \mathrm{Al}_{2} \mathrm{CuLi}$ precipitates [3-5] and may be related to disruption of order within the Li-containing matrix.

An unusual feature of these alloys is the presence of large, grain boundary precipitates which cover large area fractions of high angle grain boundaries. Vasudevan and colleagues [6-9] have published several studies which conclude that the grain boundary particles are responsible for the relative weakness of the boundaries.

Lynch et al. [10,11], on the other hand, maintain that intergranular fracture in Al-Li-X alloys is due to grain boundary segregation of Li. Lithium segregation is postulated to cause a modification of grain boundary structure and a lowering of grain boundary cohesive strength.

The publication of several conflicting explanations for low energy intergranular fracture of these alloys shows a lack of conclusive evidence for a delamination fracture mechanism. In this study some relatively new analytical techniques, namely microtexture and nanohardness, have been used to obtain more precise information on the grains adjacent to the fracture path of delamination cracks in the Al-Li alloy 2090. The grains in unrecrystallized AlLi-X alloy plate tend to be less than $20 \mu \mathrm{m}$ thick, so a plate of $1 \mathrm{~cm}$ thickness would have 500 or more grains in the thickness direction. Delamination is, however, limited to a small fraction of boundaries (Figure 1). The properties and microstructures of the grains adjacent to the delaminations may help provide a more accurate description of the fracture mechanism.

Microtexture, as a commercially available technology, is a development of the last decade [12, 13]. Microtexture studies rely on the collection of grain specific orientation information from polished sections of materials. The 
information is collected in a scanning electron microscope equipped with an electron backscattered pattern detector (EBSD) system, and uses a computer interface to position the electron beam at designated points on a tilted, polished sample; collect diffraction patterns with a phosphor screen coupled to a low-light camera and a series of computer algorithms to determine the crystallographic orientation. Data can be collected with spatial resolutions better than $0.1 \mu \mathrm{m}$ and at rates better than 50,000 points per hour. Most data is collected in an automatic mode over a grid of selected size and point separation, and the data can be displayed as maps showing various aspects of the crystallite orientation, the boundary angle between grains, and even the extent of deformation of unrecrystallized grains.

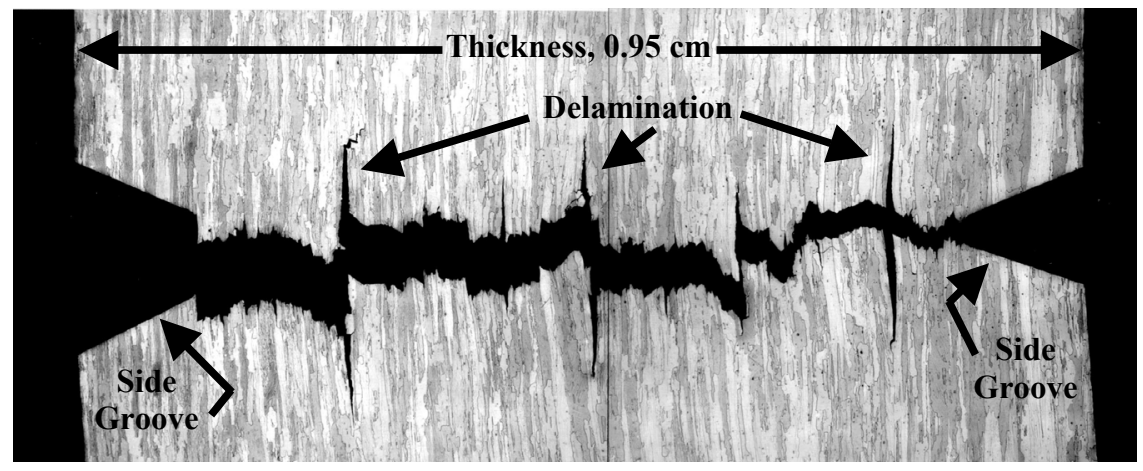

Figure 1: Cross section of a fractured specimen of $\mathrm{Al}-\mathrm{Li}$, showing delamination cracks. Growth direction of primary crack is into the plane of the page. Microtexture results show that delaminations occur along relatively few high angle boundaries.

In earlier work $[14,15]$, microtexture methods were used to examine the misorientation angles of delaminating boundaries, the possible role of special boundaries, and similarities between boundary planes and precipitate planes. These studies showed that delamination occurs at high angle boundaries in excess of $30^{\circ}$ misorientation. No conclusive correlation was found with grain boundary types, crack path and precipitate distributions [15]. However, Kalu and Wagner [14] showed that delaminations in alloy 2090 tended to occur adjacent to grains of the $\{110\}<1 \overline{1} 2>$, Brass texture component orientation. The Brass component is an extremely frequent orientation of the rolling texture in this alloy.

Nanoindentation is another recently developed technique, with a history including the last twenty or thirty years [16]. With currently available instruments it is possible to determine hardness and Young's modulus from extremely small regions. Loads as small as $1 \mathrm{nN}$ and displacements as small as $0.1 \mathrm{~nm}$ can be measured. Measurements of other properties, e.g. local yield stress, strain-hardening and creep behavior are also possible. Recent nanoindentation studies of aluminum alloys have examined the micromechanical 
properties of particle reinforced aluminum matrix composites [17, 18], and the properties of precipitate free zones in $\mathrm{Al}-\mathrm{Zn}-\mathrm{Mg}$ alloys [19].

In this study, nanoindentation was used to explore the grain-to-grain property variations of the $\mathrm{Al}-\mathrm{Cu}-\mathrm{Li}-\mathrm{Mg}-\mathrm{Zr}$ alloy 2090. Results were correlated with microtexture studies which characterized both the location of delaminations and the variation in recovery and recrystallization in the alloy plate.

\section{Experimental}

Fractured 2090 compact tension samples were sectioned normal to the fracture surface and crack direction in a region containing several delaminations. Sectioning was performed with a slow speed diamond saw. Fracture surfaces were protected by painting with an acetone soluble stop-off lacquer (Microstop), mounted in 1.25 " diameter epoxy mounts and metallographically polished with a specimen load of $\sim 4 \mathrm{lbs}$./sample. The polishing procedure involved the following abrasives and times: 600 grit $\mathrm{SiC}$ until flat, 1200 grit $\mathrm{SiC}$ for 15 minutes, $3 \mu \mathrm{m}$ Diamond paste with Struers Blue lubricant for 30 minutes on Buehler Texmet 2000 cloth, $1 \mu \mathrm{m}$ Diamond paste with Struers Blue lubricant for 30 minutes on Buehler Texmet 2000 cloth. Final polish used a 1:1:2 mixture of Stuers colloidal silica (OP-S), soap (Liquinox) and water. Final polishing was for 1 hour on Buehler Mastertex cloth. Samples were then freed from the epoxy and cleaned in acetone and alcohol with ultrasonic agitation. This method provided a flat, fairly strain-free surface, which was well suited for collection of microtexture data along the delamination cracks. The surface quality was comparable to that obtainable from electropolishing methods, but with a much flatter surface. A flat surface is important since even the minor undulations common to electropolished samples interfere with the microtexture data collection at the required $70^{\circ}$ of tilt, especially in vicinity of cracks. Grains on either side of a delamination were studied via microtexture.

A JEOL 6400 scanning electron microscope (SEM) equipped with a microtexture system was used to study microtexture and the distribution of nanoindents.

Microtexture data were collected in large sets of $\sim 40,000$ solved diffraction patterns per set, with a spatial separation of $0.5 \mu \mathrm{m}$. Analyses of the data included grain boundary misorientation; internal misorientation; discrete texture from points of the data set; identification of grains by proximity to specific, characteristic orientations (or texture components); and internal misorientation. Internal misorientation is a measure of the spread of orientations bound by a high angle boundary; i.e. it is essentially a quantification of the amount of substructure. Since the recrystallization process removes substructure, a low IM is an indication of a recrystallized condition. The data were plotted as colorcoded maps, where appropriate. Data were collected from around delamination cracks and from undeformed material. A simple method of indicating the grain orientation will be used in this paper, namely showing the distribution of indexed points on a discrete pole figure. Discrete pole figures associated with microtexture maps can be used to depict the grain orientations. 
Regions studied by microtexture were also evaluated by nanoindentation. Nanoindentation was performed with an MTS Nano Indenter XP system. Low, constant maximum load indents $(1 \mathrm{mN})$ were applied with a Berkovitch diamond indenter. Nanoindentation studies required use of an SEM for examination of the individual nanoindentations. The location of nanoindent rows in the SEM was facilitated by placement of two indents with a much larger load. Single rows of ten nanoindents were applied across a delamination, with a spacing of $5 \mu \mathrm{m}$, and the hardness values were calculated by the method of Oliver and Pharr [16]. Results from microtexture studies of delamination cracks and undeformed material were compared with nanoindentation measurements straddling delamination cracks.

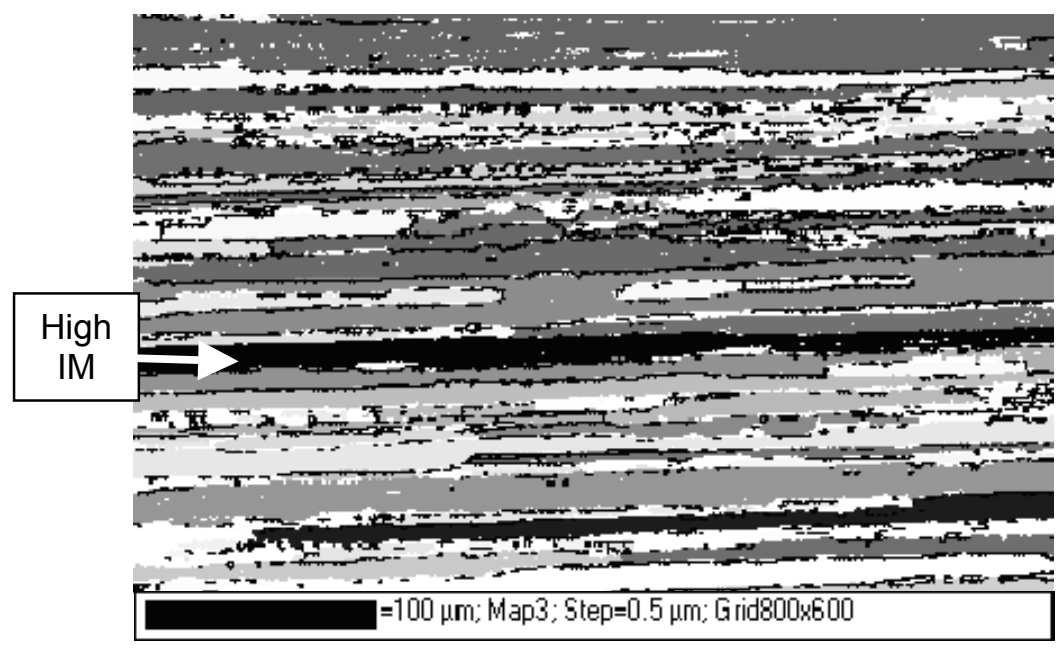

Figure 2: $\quad$ Internal misorientation (IM) map from a wide area microtexture scan of a region below a delamination crack in a L-T, J-R, 2090, compact tension sample. The range of grey levels corresponds to an IM range of $0^{\circ}$ to $5^{\circ}$. The indicated grain shows a high IM and is within the retained deformation texture brass orientation.

\section{Results and discussion}

Microtexture study of undeformed material ( $1 \mathrm{~cm}$ below a delamination crack) revealed a wide variation in internal misorientation from grain to grain. The contrast was particularly evident between grains of the retained deformation texture and neighboring, recrystallized grains with dramatically different levels of IM. The indicated grain in Figure 2, for instance, shows an internal misorientation near $5^{\circ}$, whereas some grains show IM values near $0^{\circ}$. Examination of several delaminations indicated common features which were, 
presumably, related to the fracture process. There was a tendency for fracture to occur between grains with large differences in IM. Low internal misorientation grains were expected to be "soft" due to recrystallization. Such grains were found adjacent to delaminations either as single grains or small "necklace" grains. The other side of the delamination was found to be a large, unrecrystallized grain with a greater amount of work hardening. This unrecrystallized grain was typically larger, with a much larger internal misorientation than the neighboring grains. These grains were presumed to be harder prior to aging.
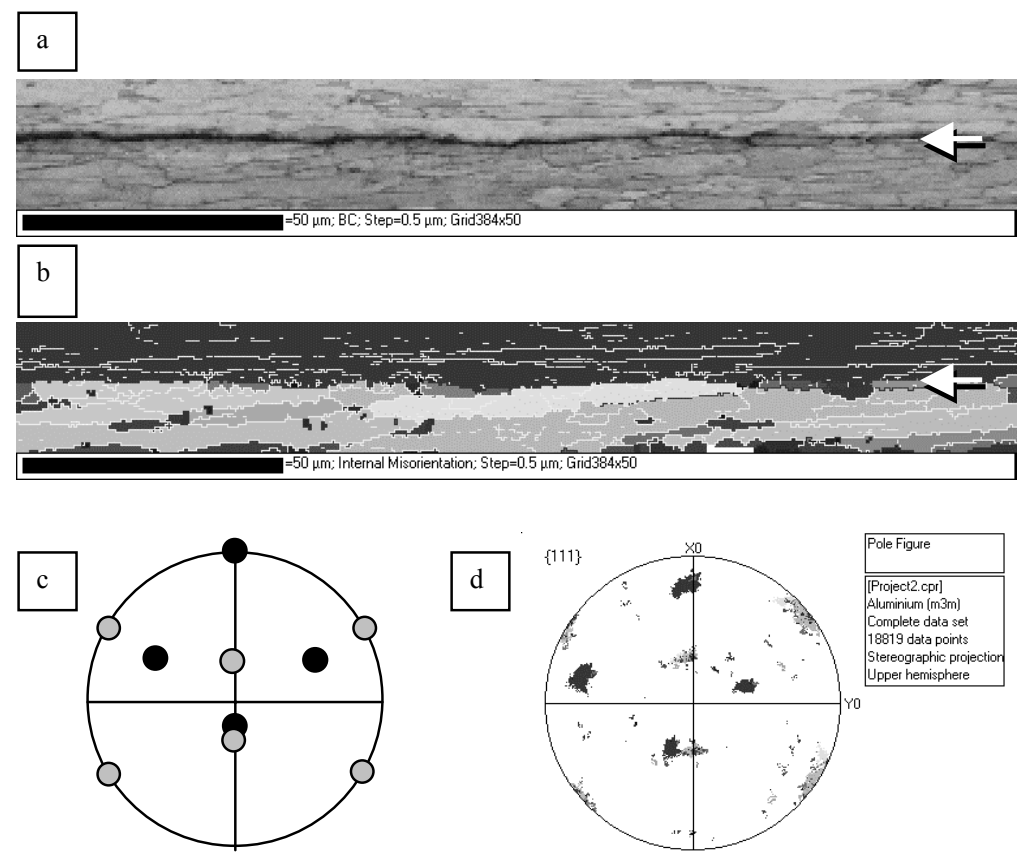

\section{GOSS O Cu}

Figure 3: Microtexture plots showing internal misorientation of grains adjacent to a delamination crack (arrows) in 2090-T8. From a T-L, J-R, compact tension sample. a) Image Quality (IQ) map, b) Internal Misorientation (IM) map, c) schematic of (111) pole figure showing ideal Goss and $\mathrm{Cu}$ orientations and d) discrete (111) pole figure from the data of $\mathrm{b}$ ). Darker grain is near a $\mathrm{Cu}$ deformation component orientation. Region below the crack is in the Goss, recrystallized orientation.

An example of this effect is shown in Figure 3, which shows microtexture maps of delamination fracture between a Goss, recrystallized grain, and a grain near the $\mathrm{Cu}$ deformation component orientation. The unrecrystallized $(\mathrm{Cu})$ grain 
shows an IM of near $5^{\circ}$, which is about twice as high as the Goss grain across the crack. Large internal misorientation was taken as an indication of high stored strain energy, such as would be expected for a grain of the deformation texture. Low internal misorientation was an indication of recrystallization subsequent to rolling, which is likely to have developed during solution heat treatment of the sheet prior to artificial aging.

For sheet or plate to be given a T8 aging treatment, a stretch of about $6-8 \%$ is applied subsequent to solution heat treatment and prior to aging. Recrystallized grains (without substructure) are then given a significant dislocation density which aids in precipitate nucleation. The increased density of precipitates increases the strength considerably. However, the grains with well developed substructure should exhibit precipitation on subgrain boundaries, and should develop an even higher dislocation density due to dislocation multiplication effects during deformation. These grains may develop greater hardness during aging. A nanoindentation study was used to investigate this possibility. Figure 4 shows a series of nanoindents traversing a delamination crack. The grain on the right side of the crack, which was near the Brass orientation, showed a hardness increase of about $20 \%$ greater than the grain across the crack. This was despite the indent being at the very edge of the crack, which might be expected to result in a low hardness value.

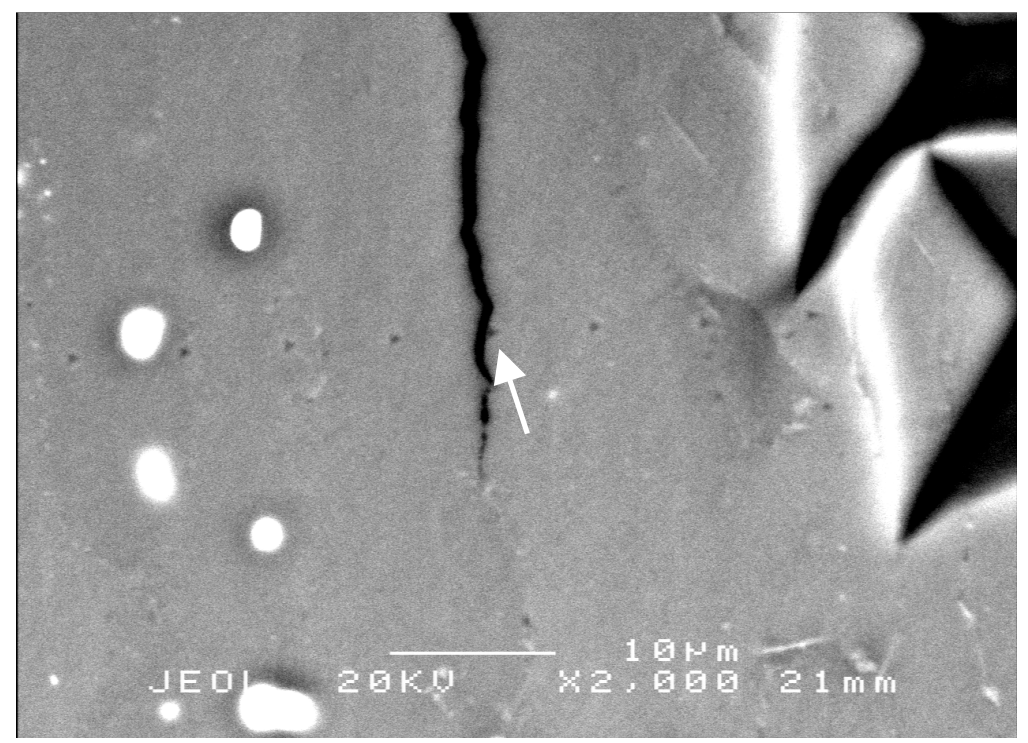

Figure 4: Scanning electron micrograph of a delamination crack and nanoindents. Longitudinal (LS) plane from a 2090 L-T, J-R test. Nanohardness indents are shown along with larger marker indents. A nanohardness increase, of about $20 \%$, was found for one point within a grain adjacent to the delamination (arrow). The higher nanohardness grain shown has a locally high IM and is close to the Brass orientation. 
Delamination frequently occurs along grain boundaries which are interfaces between hard and soft grains. Measurements of IM, texture components and direct measurements of nanohardness support this observation. This may be due to the tendency of the softer grains to preferentially deform and suffer from poor accommodation of plastic distortion at the grain boundary, since the minimum resolved shear stress would be greater in the harder grain. An additional factor may be the tendency of recrystallized grains to end their growth at obstacles, such as incoherent intermetallic particles, which establish weak interfaces at the new grain boundaries.

\section{Conclusions}

The following conclusions can be reached from this study:

Delamination occurs preferentially along interfaces between "hard" and "soft" grains, representing, in the first case, grains of the deformation texture with high stored strain energy and in the second case, recrystallized grains. This is supported by 1) texture information, which can be compared to well-known sequences in the processing history, 2) measurements of the intragranular orientation variation and 3 ) direct measurements of the nanohardness adjacent to delamination fractures.

Higher hardness is attributed to stored strain energy of some components of the unrecrystallized material vs. the softer condition of the recrystallized material.

This observation of fracture along the hard/soft interface does not eliminate any one of the mechanisms proposed for delamination fracture, but adds yet another factor.

The correlation of nanoindentation and microtexture data provide significant and new insights into the mechanical properties of $\mathrm{Al}-\mathrm{Cu}-\mathrm{Li}-\mathrm{X}$ alloys.

\section{References}

[1] Sanders, Jr., T.H., \& Starke, Jr., E.A., (eds). Al-Li Alloys I, Proceedings of the First International Aluminum-Lithium Conference, Stone Mountain, Georgia, 1980.

[2] Sanders, Jr., T.H. \& Starke, Jr., E.A., The effect of slip distribution on the monotonic and cyclic ductility of Al-Li binary alloy. Acta Metall., 30, p. 927, 1982.

[3] Csontos, A.A. \& Starke, Jr., E.A., The effect of inhomogeneous plastic deformation on the ductility and fracture behavior of age hardenable aluminum alloys. International Journal of Plasticity, 21, pp. 1097-1118, 2005.

[4] Howe, J.M. \& Vasudevan, A.K., Structure and deformation behavior of T sub 1 precipitate plates in an Al-2Li-1Cu alloy. Metall. Trans. A, 19A, p. 2911, 1988. 
[5] Crooks, R., Wang, Z., Levit, V.I. \& Shenoy, R.N., Microtexture, microstructure and plastic anisotropy of AA2195. Materials Science and Engineering A, A257(1), pp. 145-152, 1998.

[6] Jata, K.V. \& Vasudevan, A.K., Effect of fabrication and microstructure on the fracture initiation and growth toughness of Al-Li-Cu alloys. Materials Science and Engineering A, A241, pp. 104-113, 1998.

[7] Suresh, S., Vasudevan, A.K., Tosten, M. \& Howell, P.R., Acta Metall., 35, p. 25, 1987.

[8] Vasudevan, A.K. \& Doherty, R.D., Acta Metall., 35, p. 1193, 1987.

[9] Vasudevan, A.K., Ludwiczak, E.A., Baumann, S.F., Howell, P.R., Dougherty, R.D. \& Kersker, M.M., Mater. Sci. Technol., 2, p. 1205, 1986.

[10] Lynch, S.P., Materials Science and Engineering A, A136, p. 25, 1991.

[11] Lynch, S.P., Muddle, B.C. \& Pasang, T., Ductile-Brittle Fracture Transitions in 8090 All-Li Alloys. Acta mater, 49, pp. 2863-2874, 2001.

[12] Adams, B.L., Orientation Imaging Microscopy: Emerging and Future Applications. Ultramicroscopy, 67, pp. 11-17, 1997.

[13] Schwartz, A.J., Kumar, M. \& Adams, B.L., Electron Backscatter Diffraction in Materials Science, Kluwer Academic/Plenum, New York, 2000.

[14] Kalu, P.N. \& Wagner, J.A., A Microtexture Investigation of the Fracture Behavior of Al-Li Alloy, 2090-T81. The 3rd Light Weight Alloys for Aerospace Applications, ed. E.W. Lee, TMS, Warrendale, PA, pp. 157167, 1995.

[15] Hales, S.J. \& Crooks, R., Recrystallized and unrecrystallized Al-Li alloys for elevated temperature service. Proc. 3rd International Conf. on Recrystallization and Related Phenomena, ed. T.R. McNelley, MIAS, pp. 511-518, 1997.

[16] Oliver, W.C. \& Pharr, G.M., An Improved Technique for Determining Hardness and Elastic Modulus Using Load and Displacement Sensing Indentation Experiments. J. Mater. Res., 7(6), pp. 1564-1583, 1992.

[17] Torralba, J.M., Velasco, F., Costa, C.E., Vergara, I. \& Caceres, D., Mechanical behaviour of the interphase between matrix and reinforcement of Al 2014 matrix composites reinforced with $\left(\mathrm{Ni}_{3} \mathrm{Al}\right)_{\mathrm{p}}$. Composites: Part A, 33, pp. 491-496, 2002.

[18] Liu, C., Qin, S., Zhang, G. \& Naka, M., Micromechanical properties of high fracture performance SiCp-6061/6061 Al composite. Materials Science and Engineering A, A332, pp. 203-209, 2002.

[19] Ogura, T., Hirosawa, S. \& Sato, T., Quantitative characterization of precipitate free zones in $\mathrm{Al}-\mathrm{Zn}-\mathrm{Mg}(-\mathrm{Ag})$ alloys by microchemical analysis and nanoindentation measurement. Science and Technology of Advanced Materials, 5, pp. 491-496, 2004. 